\title{
Índices produtivos de fêmeas suínas alimentadas com dietas de gestação e lactação suplementadas com óleos essenciais de orégano e alecrim: avaliação de leitegadas
}

\author{
Production index of the sows fed diets supplemented in the parturition and lactation \\ with essential oils of oregano and rosemary: evaluation of litters
}

\section{Carlos Augusto Rigon Rossi ${ }^{\mathrm{I}^{*}}$ Marcelo Soares ${ }^{\mathrm{I}}$}

\section{RESUMO}

Este estudo avaliou os índices produtivos de matrizes suínas alimentadas com dietas contendo uma mescla líquida de óleos essenciais. Foram utilizadas 250 matrizes de ordens de parto (OP) entre um a oito, com duas dietas experimentais na gestação e duas na lactação (dietas controle e com 200ppm de óleos essenciais). O delineamento experimental foi o de blocos ao acaso, em um arranjo fatorial $2 \times 2$ (tratamentos na gestação e na lactação) com as matrizes e leitegadas como unidade experimental. $O$ peso vivo médio da leitegada ao desmame e o número de desmamados foram $8,0 \%$ e $3,8 \%$ superiores $(P<0,05)$, respectivamente, para os leitões filhos de matrizes suplementadas com óleos essenciais. A temperatura corporal das fêmeas do controle e OP cinco, avaliadas no período pré-parto e durante o parto, foi 4,4\% e 3,5\% superiores $(P<0,05)$ aos óleos essenciais, respectivamente. A adição de óleos essenciais na dieta de matrizes no final de gestação e no início da lactação aumentou o número de leitões desmamados e o peso de leitegada. As fêmeas suplementadas com óleos essenciais não apresentaram temperatura e sinais clínicos condizentes com disgalactia.

Palavras-chave: matrizes suínas, ordem de parto, Origanum vulgare, Rosmarinus officinalis labiatae.

\section{ABSTRACT}

The study evaluated the production index of sows fed diets containing a blend of essential oils. A total of 250 sows of parturition orders $(P O)$ between one to eight, with two experimental diets during gestation and in the lactation (control diet with 200ppm and essential oils). The experimental design was a randomized blocks in a 2x2 factorial arrangement (treatments during pregnancy and lactation) with the sows and piglets as experimental unit. The average live weight of piglets at weaning and number of weaned were $8.0 \%$ and $3.8 \%$ higher $(P<0.05)$, respectively for piglets from mothers supplemented with essential oils. The body temperature of females of the control and PO five, evaluated in the pre-parturition and in the parturition, was $4.4 \%$ and $3.5 \%$ higher $(P<0.05)$ to essential oils, respectively. The addition of essential oils in the diet of sows in late pregnancy and early lactation increased the number of piglets weaned and litter weight. Females supplemented with essential oils, did not show temperature and clinical signs consistent with disgalactia.

Key words: Origanum vulgare, parturition order, Rosmarinus officinalis labiatae, sows.

\section{INTRODUÇÃO}

A suinocultura é uma atividade com excelente posição no cenário internacional, devido ao melhoramento genético e à nutrição de alta qualidade. Na atividade, os índices de produtividade e retorno econômico são possíveis através de um controle rigoroso do manejo sanitário e nutricional em todas as fases de criação do suíno. Entretanto, uma das etapas que demanda maior preocupação é a fase de lactente, pois, quando submetida a manejo inadequado, pode provocar prejuízos à produção.

A eficiência na fase de leitão lactente depende principalmente da produção de leite da fêmea suína (BARROS et al., 2008). Assim, a integridade do complexo mamário tem importância cada vez maior para uma adequada criação e desenvolvimento dos leitões até o desmame (BORTOLOZZO \& WENTZ, 2007). É interessante lembrar que a produção de leite é influenciada pela genética e isso permite selecionar as fêmeas que irão desmamar leitões mais pesados. Por sua vez, as falhas

\footnotetext{
'Departamento de Clínica de Grandes Animais, Universidade Federal de Santa Maria (UFSM), 97105-900, Santa Maria, RS, Brasil. E-mail: carlos.rossi.mv@gmail.com.*Autor para correspondência. 
lactacionais levam ao comprometimento na produção de leite e susceptibilidade do leitão à hipoglicemia, perdas neonatais e baixo desempenho dos leitões (FALCETO et al., 2012).

A necessidade de garantir os resultados zootécnicos e econômicos na produção de suínos incentivou a incorporação rotineira de antibacterianos (promotores de crescimento) nas rações destinadas às fases do processo produtivo. Entretanto, o uso intenso desses produtos restringiu as exportações de carne e produtos derivados. Nesse sentido, novas alternativas que garantam o desempenho animal, a qualidade do produto final e a redução de resíduos indesejáveis à saúde do consumidor estão sendo cientificamente consideradas. Pesquisas têm sido realizadas com prebióticos, enzimas, ácidos orgânicos e extratos vegetais. Esses últimos, representados pelos óleos essenciais, são formados por uma mistura complexa de substâncias voláteis, geralmente lipofílicas, que possuem componentes como hidrocarbonetos terpênicos, álcoois simples, aldeídos, cetonas, fenóis, ésteres e ácidos orgânicos (COSTA et al., 2007). Os efeitos observados in vitro são vários, o que justifica as pesquisas para determinar as combinações e níveis de inclusão dos óleos essenciais às dietas ou o desenvolvimento de produtos, de uso oral, para melhorar o desempenho e a produção animal (HERNANDEZ et al., 2004).

Os óleos essenciais interferem na microbiota intestinal (efeito antimicrobiano), melhoram a digestibilidade e a absorção dos nutrientes, além de estimular a resposta imune e induzir modificações morfo-histológicas do trato gastrintestinal (COSTA et al., 2007). Entre os constituintes dos óleos essenciais, o óleo de alecrim (Rosmarinus officinalis) é considerado um potente antioxidante (VELLOSO \& PEGLOW, 2003). Dessa forma, é possível sugerir que a inclusão de óleos essenciais diretamente na dieta possa expressar a atividade antioxidante nos tecidos vivos e proteger os animais de agentes oxidantes. Já o suplemento com orégano (Origanum vulgare), na dieta de fêmeas suínas, reduz a taxa de mortalidade das fêmeas, a taxa de eliminação de fêmeas durante a lactação, aumenta a taxa de parição e aumenta o número de leitões nascidos vivos por leitegada (MAUCH \& BILKEI, 2004).

Pelas propriedades individuais e ação sinérgica de seus princípios ativos, o uso de óleos essenciais em fêmeas suínas, via oral, no período de gestação e na lactação, pode melhorar os índices produtivos, além de reduzir a incidência de disgalactia. Embora existam informações positivas relacionadas ao sinergismo dos constituintes dos óleos essenciais, seu uso terapêutico no controle dos sinais clínicos da disgalactia em porcas é incipiente e pouco conclusivo. Assim, o objetivo deste trabalho foi avaliar o efeito da adição de uma mescla líquida de óleos essenciais, via oral, em dietas de matrizes no final de gestação e no terço inicial da lactação, sobre seu desempenho produtivo e de suas leitegadas.

\section{MATERIAL E MÉTODOS}

A mescla de óleos essenciais foi constituída por $5 \%$ de orégano (Origanum vulgare) (60\% de carvacrol e 15\% de timol), $2 \%$ de alecrim (Rosmarinus officinalis labiatae) e veículo inerte aquoso (água deionizada). A seleção dos óleos essenciais foi realizada a partir de pesquisas prévias realizadas in vitro com frangos de corte (SANTURIO et al., 2011). O experimento foi realizado em granja comercial $\left(29^{\circ} 37^{\prime} 35.95^{\prime \prime}\right.$ latitude sul e $56^{\circ} 32^{\prime}$ 29.85”' longitude oeste), no período entre novembro e dezembro de 2011. Foram utilizadas 250 fêmeas suínas geneticamente homogêneas, de ordens de parto entre um a oito. As fêmeas suínas foram transferidas para a maternidade, em média, quatro dias antes do provável parto e alojadas em celas individuais. As fêmeas, independente da ordem de parto (OP) e seus leitões foram mantidos dentro da zona de conforto térmico para cada categoria. Foram utilizadas quatro dietas experimentais, de acordo com as exigências nutricionais estabelecidas pelas Tabelas Brasileiras para Aves e Suínos (ROSTAGNO et al., 2011). As dietas foram distribuídas em: gestação (controle e controle+adição de 200ppm da mescla de óleos essenciais) e lactação (controle e controle+adição de 200ppm da mescla de óleos essenciais). As fêmeas suínas receberam as dietas experimentais a partir dos 65 dias de gestação na quantidade $2,5 \mathrm{~kg}$ animal ${ }^{-1} \mathrm{dia}^{-1}$ até 110 dias de gestação. Entre os dias 110 e 113 de gestação, as fêmeas receberam $2 \mathrm{~kg}$ dia $^{-1}$ de ração lactação, seguido de $1 \mathrm{~kg}$ de ração/animal-1 dia $^{-1}$ até o parto. Após o parto, as fêmeas suínas receberam ração de lactação até o desmame dos leitões. Esse fornecimento aumentou gradativamente até que o consumo voluntário estabilizasse (em torno do sexto dia de lactação), quando as fêmeas lactantes passaram a receber ração de lactação sem óleos essenciais, farelada à vontade até o desmame.

A alimentação foi fornecida quatro vezes ao dia para manter um suprimento constante de ração fresca disponível para os animais. Foram avaliados: (a) leitões - número de nascidos totais, número de nascidos vivos, peso vivo médio do leitão 
ao nascimento, peso vivo médio da leitegada, peso médio do leitão aos sete dias de vida, peso vivo médio do leitão ao desmame, peso vivo médio da leitegada ao desmame, número de desmamados e (b) matrizes temperatura corporal (período pré-parto, durante o parto, 12 horas pós-parto e 24 horas pós-parto) em relação à OP e duração do parto, apetite, inapetência e nível de produção de leite (hiperemia da glândula mamária) conforme a literatura (WALLER et al., 2002).

O delineamento experimental foi o de blocos ao acaso, em um arranjo fatorial $2 \times 2$ (dois tratamentos na gestação e dois tratamentos na lactação), com as matrizes e leitegada como unidade experimental. Os tratamentos foram blocados de acordo com as ordens de parto das matrizes. A pressuposição da normalidade dos dados foi testada através do teste de Ryan-Joiner (teste similar ao Shapiro-Wilk), sendo que a hipótese nula expressa que os dados apresentam distribuição normal. Atendida essa pressuposição, os dados de desempenho produtivo das fêmeas suínas e de suas leitegadas foram submetidos à análise de variância pelo procedimento GLM e as eventuais diferenças entre médias foram comparadas pelo teste de Tukey, em nível de 5\% de probabilidade. As análises estatísticas foram realizadas com o programa estatístico Minitab (MCKENZIE \& GOLDMAN, 1999).

\section{RESULTADOS E DISCUSSÃO}

Não foram encontradas diferenças $(\mathrm{P}>0,05)$ entre os tratamentos (Tabela 1) para o número de nascidos totais, número de nascidos vivos, peso vivo médio do leitão ao nascimento, peso vivo médio da leitegada, peso médio do leitão aos sete dias de vida e peso vivo médio do leitão ao desmame. No entanto, o peso vivo médio da leitegada ao desmame e o número de desmamados foi $8,0 \%$ superior $(\mathrm{P}<0,05)$ e $3,8 \%$ superior $(\mathrm{P}<0,05)$, respectivamente, para os leitões filhos de fêmeas suínas suplementadas com óleos essenciais. Os resultados do número de nascidos vivos encontrados são semelhantes aos observados em outro trabalho com extratos vegetais (orégano, cinamomo e pimenta), quando os autores observaram uma redução na mortalidade de leitões do nascimento ao desmame (MATYSIAK et al., 2012). Outro estudo demonstrou, no geral, aumento de 0,78 leitões por matriz, na produção subsequente para fêmeas suínas alimentadas com dietas contendo orégano (ALLAN \& BILKEI, 2005).

Os resultados de desempenho dos leitões observados foram semelhantes aos reportados na literatura (ARIZA-NIETO et al., 2011). No entanto, esses autores observaram que os leitões, filhos de matrizes suplementadas com óleos essenciais no período de gestação, apresentaram maior ganho médio diário de peso, maior consumo de energia e maior consumo de leite nos dias 16 a 19 de lactação. O potencial de crescimento do leitão, por sua vez, é influenciado, entre numerosos fatores, pelo consumo de leite. Segundo NOBLET et al. (1990), esse efeito é mais pronunciado na segunda semana da lactação, quando o déficit na ingestão de energia é evidente.

Os resultados positivos, sobre o peso médio da leitegada ao desmame e o número de desmamados, podem ser atribuídos ao maior conteúdo de lactose presente no leite de matrizes suplementadas com óleos essenciais. São descritos na literatura índices $14 \%$ superiores de lactose na composição do leite de matrizes suplementadas com extratos vegetais (orégano, cinamomo e pimenta) (MATYSIAK et al., 2012). Esses autores sugerem que níveis mais altos de lactose presentes no leite das matrizes reduzem a hipoglicemia e a mortalidade neonatal. Em relação à

Tabela 1 - Índices produtivos de leitões filhos de porcas suplementadas ou não com óleos essenciais durante a gestação e lactação.

\begin{tabular}{|c|c|c|c|c|c|c|c|c|c|}
\hline Tratamentos (T) & $\mathrm{NF}$ & NT & $\mathrm{NV}$ & $\mathrm{PV}_{\mathrm{mn}}$ & $\mathrm{PV}_{\mathrm{ml}}^{(1)}$ & $\mathrm{PV}_{\mathrm{ml}}$ & $\mathrm{PV}_{\text {mld }}$ & $\mathrm{PV}_{\text {ld }}$ & $\mathrm{ND}^{(2)}$ \\
\hline Controle & 125 & 13,64 & 12,50 & 1,45 & 18,56 & 2,77 & 5,34 & $54,60^{\mathrm{b}}$ & $10,17^{\mathrm{b}}$ \\
\hline Óleos essenciais & 125 & 13,60 & 12,60 & 1,47 & 18,86 & 2,66 & 5,57 & $59,00^{\mathrm{a}}$ & $10,56^{\mathrm{a}}$ \\
\hline Dpr & & 1,98 & 1,58 & 0,25 & 3,02 & 0,62 & 0,72 & 11,37 & 1,27 \\
\hline \multicolumn{10}{|l|}{ Probabilidade } \\
\hline $\mathrm{T}$ & & 0,92 & 0,65 & 0,82 & 0,94 & 0,20 & 0,07 & 0,01 & 0,01 \\
\hline OP & & 0,90 & 0,88 & 0,06 & 0,01 & 0,34 & 0,89 & 0,60 & 0,01 \\
\hline $\mathrm{T} \times \mathrm{DP}$ & & 0,92 & 0,98 & 0,84 & 0,60 & 0,32 & 0,16 & 0,30 & 0,62 \\
\hline
\end{tabular}

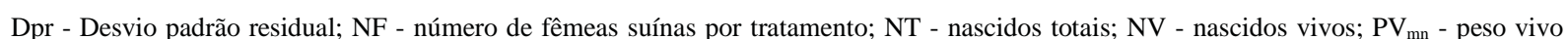
médio leitão ao nascimento; $\mathrm{PV}_{\mathrm{ml}}$ - peso vivo médio da leitegada; $\mathrm{PV}_{\mathrm{ml} 7}$ - peso médio do leitão aos sete dias de vida; $\mathrm{PV}$ mld - peso vivo médio do leitão ao desmame; $\mathrm{PV}_{\mathrm{ld}}$ - peso vivo médio da leitegada ao desmame; ND - número de desmamados; OP - ordem de parto; DP - duração do parto; ${ }^{\mathrm{a}, \mathrm{b}}$ letras diferentes na mesma coluna diferem pelo Teste de Tukey $(\mathrm{P}<0,05)$. ${ }^{(1)}$ Equação de regressão para a $\mathrm{PV}$ ml $(Y i j=15,8+0,02$ OP); ${ }^{(2)}$ Equação de regressão para a ND (Yij=19,6-0,08 OP). 
ação imunoestimulante, foram observadas maiores concentrações de IgG e IgA no leite de fêmeas suínas suplementadas com óleos essenciais (WANG et al., 2008). Nesse sentido, a proteção imunológica passiva pode ter sido iniciada nos leitões pelas concentrações crescentes de imunoglobulinas presentes no colostro ingerido nas primeiras horas de vida. O isotipo de imunoglobulina predominante no colostro é IgG (ARIZA-NIETO et al., 2011). À medida que a lactação evolui, as concentrações de IgG diminuem e a IgA torna-se a imunoglobulina importante no leite da fêmea suína (OSWALD, 2006). A IgG está envolvida na resposta secundária ao anticorpo, ao passo que a IgA tem um papel crítico na imunidade de mucosa (GASKINS, 1997). Assim, no presente trabalho, é possível estimar que o peso médio da leitegada e o maior número de leitões desmamados resultaram do efeito positivo dos óleos essenciais administrados às fêmeas suínas. Estas provavelmente apresentaram maior conteúdo de lactose e maiores concentrações de IgG e IgA presentes no leite. Esse fato pode ter contribuído para a redução da hipoglicemia e a mortalidade neonatal, bem como favoreceu a ação imunoestimulante.

A temperatura corporal das fêmeas do grupo controle e OP cinco, avaliadas no período préparto e durante o parto (Tabela 2), foi 4,4\% e 3,5\% superior $(\mathrm{P}<0,05)$ ao tratamento com óleos essenciais, respectivamente. As fêmeas de OP oito do grupo controle apresentaram temperatura corporal, 24 horas pós-parto, $1,0 \%$ superior $(\mathrm{P}<0,05)$ em relação ao tratamento com óleos essenciais. Em nosso trabalho, as fêmeas suínas suplementadas com óleos essenciais, não apresentaram elevação de temperatura e sinais clínicos condizentes com disgalactia. No entanto, as fêmeas suínas do grupo controle apresentaram sintomalogia clínica de disgalactia, principalmente as OP cinco e oito. A elevação da temperatura, associada aos sinais clínicos de disgalactia, foi observada nas avaliações no período pré-parto e durante o parto.

A definição da temperatura mínima, acima da qual se considera hipertermia em uma fêmea suína no período puerperal, é motivo de discussão (BORTOLOZZO \& WENTZ, 2007). Na fase de gestação, a temperatura retal de fêmeas sadias varia entre $38,3^{\circ} \mathrm{C}$ e $38,7^{\circ} \mathrm{C}$, sendo que, após o parto e na lactação, é reportado um aumento de $1^{\circ} \mathrm{C}$ para esse intervalo (KLOPFENSTEIN et al., 1999). As mudanças metabólicas do pós-parto, principalmente as envolvidas na produção de leite, aumentam a produção interna de calor e esse tem que ser dissipado para a manutenção da temperatura corporal. Além disso, podem colaborar para o incremento na temperatura corporal o fato das fêmeas estarem sendo alimentadas ad libitum com uma ração altamente energética, o meio ambiente mantido mais aquecido para os leitões e o fato de as matrizes não terem amplo acesso a um piso frio para perder o excesso de calor. Somam-se a isso os períodos de estresse térmico associados ao verão (BORTOLOZZO \& WENTZ, 2007). Todos esses aspectos são fundamentais para diferenciar a denominada hipertermia fisiológica da patológica. Nesse contexto, utilizando o bom senso em estimar possíveis agentes causais de hipertermia, associados, principalmente, às instalações e meio ambiente, alguns autores consideram "fêmeas problema” aquelas que não se alimentam e apresentam temperatura retal acima de $40,3^{\circ} \mathrm{C}$ (KLOPFENSTEIN et al., 1999). Outros trabalhos consideram "fêmeas problema" aquelas com temperatura igual ou superior a $39,5^{\circ} \mathrm{C}$ e que apresentam sinais clínicos ou alterações comportamentais relacionadas com a disgalactia (PREISSLER et al., 2012).

Em uma rápida reflexão sobre a ocorrência de disgalactia em fêmeas suínas, as endotoxinas bacterianas podem ter influência no aumento da temperatura corporal (BORTOLOZZO \& WENTZ, 2007). Essas endotoxinas lipopolissacarídicas podem suprimir a liberação do hormônio envolvido na iniciação da lactação, a prolactina, por parte da hipófise anterior, diminuir os hormônios tireoidianos circulantes e aumentar a concentração de cortisol (WANG et al., 2006). Essas alterações afetam, adversamente, a produção e secreção de colostro e leite. O colostro, por sua vez, possui alto teor energético e imunológico e qualquer alteração (quantidade ou qualidade) resultará no comprometimento do desenvolvimento dos leitões. Assim, a adição de orégano na dieta de fêmeas suínas estabiliza a microflora intestinal, diminui a população de microorganismos indesejáveis e aumenta a digestibilidade dos alimentos (ALLAN \& BILKEI, 2005). Nesse sentido, a ativação do sistema imunitário pós-parturiente pode ser positivamente influenciado pela diminuição dos efeitos deletérios da resposta imunitária retardada e redução da atividade de leucócitos no útero da porca no pós-parto. Consequentemente, a involução uterina pode ser acelerada e a porca melhor protegida contra infecções urogenitais no pós-parto. Como resultado da rápida involução uterina, há redução de 66,4\% e 64\%, respectivamente, quanto à incidência de doenças urogenitais e disgalactia, respectivamente, e aumento na taxa de parto subsequente (AMRIK \& BILKEI, 2004). Estudos anteriores confirmam que o uso de óleos essenciais de orégano na dieta de fêmeas suínas 
Tabela 2 - Temperatura corporal de porcas suplementadas ou não com óleos essenciais e avaliadas no período pré-parto, durante o parto, 12 horas pós-parto e 24 horas pós-parto.

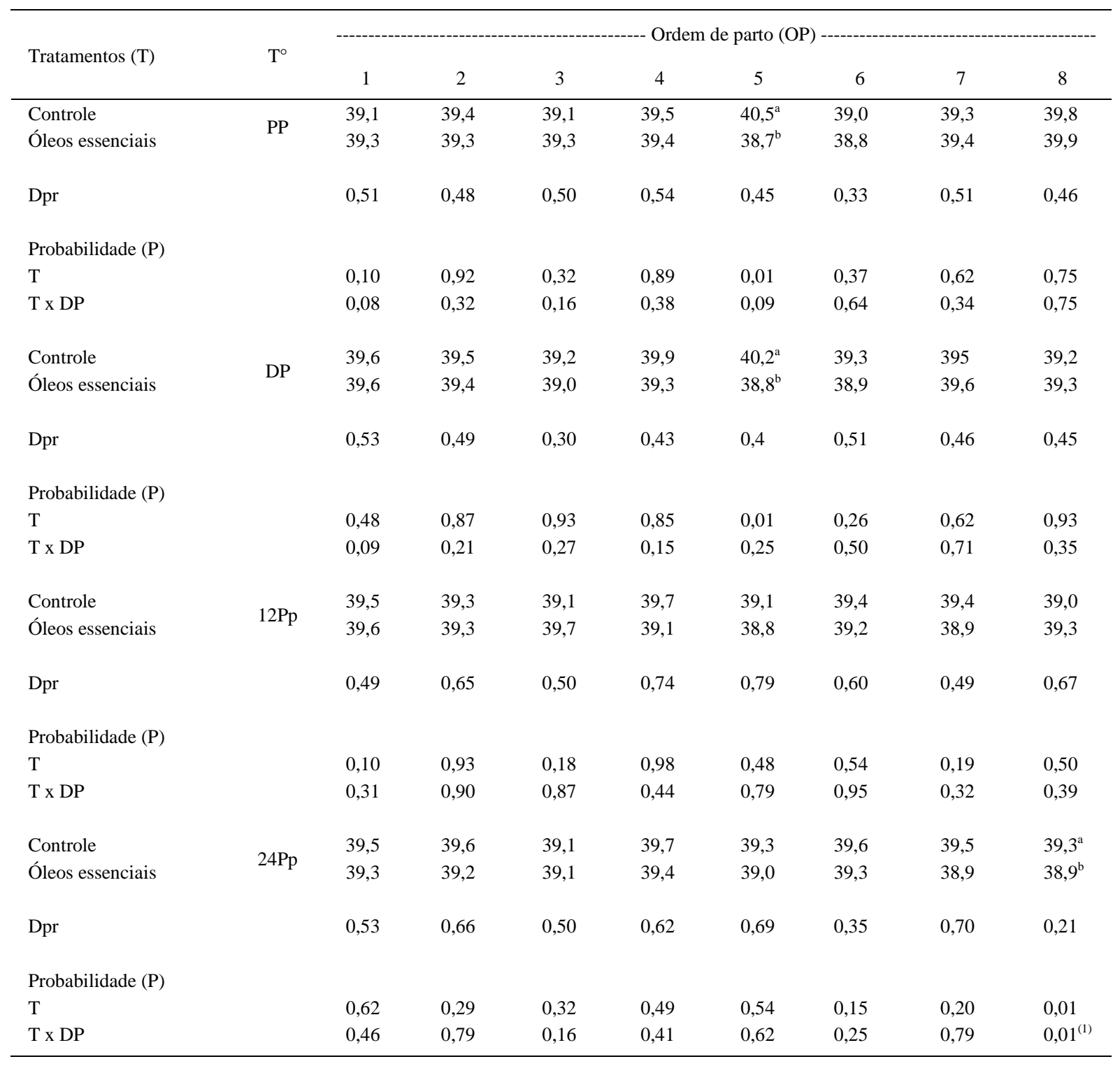

Dpr - Desvio padrão residual; $\mathrm{T}^{\circ}$ - Temperatura corporal da porca; $\mathrm{PP}$ - $\mathrm{T}^{\circ}$ pré-parto; $\mathrm{DP}$ - $\mathrm{T}^{\circ}$ durante o parto; $12 \mathrm{Pp}$ - $\mathrm{T}^{\circ} 12$ horas pós-parto; 24Pp - T 24 horas pós-parto; DP - duração do parto; T x DP - interação; ${ }^{\text {a, b }}$ letras diferentes na mesma coluna diferem pelo Teste de Tukey $(\mathrm{P}<0,05) ;{ }^{(1)} \mathrm{T}^{\circ} 24 \mathrm{Pp}(\mathrm{Yij}=39,5-0,03 \mathrm{OP})$.

atua como promotores alternativos de desempenho, com funções antibacterianas, melhoradores de apetite e auxiliares na digestão. Esses atuam também como estimuladores do desempenho reprodutivo e produção de leite, bem como efeitos positivos sobre o desempenho dos leitões (CABRERA et al., 2008). Assim, os resultados obtidos no presente estudo mostraram que a administração de óleos essenciais à dieta de matrizes em final de gestação e início da lactação foi eficaz no apoio a saúde das fêmeas.

\section{CONCLUSÃO}

A adição de uma mescla líquida de óleos essenciais via oral, em dietas de matrizes no final de gestação e início da lactação, favoreceu o aumento do número de leitões desmamados e o peso de leitegada. As matrizes suplementadas com óleos essenciais não apresentaram elevação de temperatura ou sinais clínicos condizentes com disgalactia. 


\section{COMITÊ DE ÉTICA E BIOSSEGURANÇA}

Declaramos que os animais utilizados em experimentação que originou o artigo "Índices produtivos de matrizes suínas alimentadas com dietas contendo óleos essenciais na gestação e lactação”, encaminhado para publicação na revista Ciência Rural, foram avaliados sob os princípios do bem estar animal.

\section{REFERÊNCIAS}

ALLAN, P.; BILKEI, G. Oregano improves reproductive performance of sows. Theriogenology, v.63, p.716-721, 2005. Disponível em: <http://www.sciencedirect.com/science/article/ pii/S0093691X04001529>. Acesso em: 11 jan. 2012. doi:http:// dx.doi.org/10.1016/j.theriogenology.2003.06.010.

AMRIK, B.; BILKEI, G. Influence of farm application of oregano on performances of sows. Canadian Veterinary Journal, v.45, p.374-677, 2004. Disponível em: <http://www.ncbi.nlm.nih.gov/ pmc/articles/PMC546446/pdf/cvj45pg674.pdf>. Acesso em: 11 jan. 2012.

ARIZA-NIETO, C. et al. Effect of dietary supplementation of oregano essential oils to sows on colostrum and milk composition, growth pattern and immune status of suckling pigs. Journal of Animal Science, v.89, p.1079-1089, 2011. Disponível em: <http:// jas.fass.org/content/89/4/1079.abstract>. Acesso em: 13 jan. 2012. doi:10.2527/jas.2010-3514.

BARROS, L. R. et al. Distúrbios de impacto econômico na produção de suínos: agalaxia. REDVET - Revista Electrónica de Veterinária, v.9, p.1-13, 2008. Disponível em: <http://www. veterinaria.org/revistas/redvet/n070708/070807.pdf>. Acesso em: 06 de jan. 2012.

BORTOLOZZO, F.P.; WENTZ, I. Síndrome da disgalactia pósparto na porca: uma visão atual do problema. Acta Scientiae Veterinariae, v.35, p.157-164, 2007. Disponível em: <http:// www.ufrgs.br/actavet/35-suple-1/Simposio\%20suinos.pdf > . Acesso em: 15 fev. 2012.

CABRERA, R. et al. Oregano essential oil in sow diets improves sows and piglet performance. American Association of Swine Veterinarians, 2008. Disponível em: <http://www. ralcoanimalhealth.com/regano/PDFS/swine/2_Oregano_ essential_oil.pdf>. Acesso em: 10 jan. 2012.

COSTA, L.B. et al. Extratos vegetais como alternativas aos antimicrobianos promotores de crescimento para leitões recémdesmamados. Revista Brasileira de Zootecnia, v.36, p.589595, 2007. Disponível em:<http://www.scielo.br/pdf/rbz/v36n3/ a11v36n3.pdf >. Acesso em: 19 jan. 2012. doi:http://dx.doi. org/10.1590/S1516-35982007000300011.

FALCETO, M.V. et al. Lactación y etiología del síndrome de disgalactia posparto en la cerda. Published in IVIS - SUIS, v.86, p.14-22, 2012. Disponível em: <http://www.ivis.org/journals/ suis/86/2.pdf>. Acesso em: 17 mar. 2012.

GASKINS, H.R. Immunological aspects of host/microbiota interactions at the intestinal epithelium. In: MACKIE, R.I. et al. Gastrointestinal Microbiology. New York: Chapman \& Hall, 1997. p.537-587.
HERNANDEZ, F. et al. Influence of two plant extracts on broilers performance, digestibility, and digestive organ size. Poultry Science, v.83, p.169-174, 2004. Disponível em:<http://ps.fass.org/ content/83/2/169.abstract>. Acesso em: 08 jan. 2012.

KLOPFENSTEIN, C. et al. Diseases of the mammary glands and lactation problems. In. LEMAN, A.D. et al. Diseases of Swine. Ames: Iowa State University, 1999. p.833-860.

MATYSIAK, B. et al. The effect of plant extracts fed before farrowing and during lactation on sow and piglet performance. South African Journal of Animal Science, v.42, p.15-21, 2012. Disponível em: <http://www.ajol.info/index.php/sajas/article/viewFile/74457/65084>. Acesso em: 05 fev. 2012. doi: http://dx.doi.org/10.1590/S010384782006000200039 .

MAUCH, C.; BILKEI, G. Strategic application of oregano feed supplements reduces sow mortality and improves reproductive performance - a case study. Journal of Veterinary Pharmacology and Therapeutics, v.27, p.61-63, 2004. Disponível em:<http:// dx.doi.org/10.1046/j.0140-7783.2003.00531.x>. Acesso em: 06 jan. 2012. doi:10.1046/j.0140-7783.2003.00531.x.

MCKENZIE, J.; GOLDMAN, R.N. The student edition of minitab for windows manual. Softcover ed.12. Belmont: Addison-Wesley Longman, Incorporated, 1999. 592p.

NOBLET, J. et al. Energy utilization in pregnant and lactating sows: modeling of energy requirements. Journal of Animal Science, v.68, p.562-572, 1990. Disponível em:<http://jas.fass. org/content/68/2/562.abstract>. Acesso em: 07 jan. 2012.

OSWALD, I.P. Role of intestinal epithelial cells in the innate immune defence of the pig intestine. Veterinary Research, v.37, p.359-368, 2006. Disponível em: <http://dx.doi.org/10.1051/ vetres:2006006>. Acesso em: 10 mar. 2012. doi:http://dx.doi. org/10.1051/vetres:2006006.

PREISSLER, R. et al. Estimation of variance components for postpartum dysgalactia syndrome in sows. Journal of Animal Breeding and Genetics, v.129, p.98-102, 2012. Disponível em: <http://dx.doi.org/10.1111 /j.1439-0388.2011.00969.x>. Acesso em: 25 fev. 2012. doi:10.1111/j.1439-0388.2011.00969.x.

ROSTAGNO, H.S. et al. Composição de alimentos e exigências nutricionais. In: Tabelas brasileiras para aves e suínos. Editor: Horácio Santiago Rostagno - 3. ed. - Viçosa: UFV, 2011. p.141.

SANTURIO, D.F. et al. Atividade antimicrobiana de óleos essenciais de condimentos frente a amostras de Escherichia coli isoladas de aves e bovinos. Ciência Rural, v.41, p.1051-1056, 2011. Disponível em: <http://www.scielo.br/pdf/cr/2011nahead/ a0511cr4430.pdf>. Acesso em: 07 jan. 2012. doi:http://dx.doi. org/10.1590/S0103-84782011005000067.

VELLOSO, C.C.; PEGLOW, K. Plantas Medicinais. Coleção aprendendo a fazer melhor-4. Porto Alegre: EMATER/RSASCAR, 2003. 83p.

WALLER, C.M. et al. Effect of periparturient diseases accompanied by excessive vulval discharge and weaning to mating interval on sow reproductive performance. Australian Veterinary Association, v.80, p.545-549, 2002. Disponível em: <http:// 
espace.library.uq.edu.au/view/UQ:62617>. Acesso em: 13 mar. 2012. doi: http://dx.doi.org/10.1111/j.1751-0813.2002.tb11033.x.

WANG, J. F. et al. The influence of intramammary lipopolysaccharide infusion on serum Ca, P, vitamin D, cytokines and cortisol concentrations in lactating sows. Journal of Veterinary Medicine Series A, v.53, p.113-118, 2006. Disponível em: <http://dx.doi.or g/10.1111/j.1439-0442.2006.00804.x>. Acesso em: 26 mar. 2012. doi:10.1111/j.1439-0442.2006.00804.x.
WANG, Q. et al. Effects of phytogenic substances on growth performance, digestibility of nutrients, faecal noxious gas content, blood and milk characteristics and reproduction in sows and litter performance. Journal of Animal and Feed Sciences, v.17, p.50-60, 2008. Disponível em: <http:// www.ifzz.pl/en/publications/journal-of-animal-and-feedsciences/contents-from-2006-yr/vol-17-2008-r/no-1?sobi 2 Task=sobi2Details\&catid $=22 \&$ sobi2Id=86>. Acesso em: 10 fev. 2012.

Ciência Rural, v.43, n.11, nov, 2013. 